\title{
Bibliometric and Systemic Analysis of Production Planning Optimization
}

\author{
Ruan R. F. F. CHAGAS ${ }^{1}$, Paulo H. MODESTI and Milton BORSATO \\ Universidade Tecnológica Federal do Paraná (UTFPR), Curitiba-PR, Brazil
}

\begin{abstract}
Having good production planning is essential to companies who need to maximize the use of their resources and boost their profits. However, to formulate efficient production planning is necessary to consider many variables. That makes analytical solutions almost impossible, forcing companies to use computational methods to solve this kind of problem. Even so, because of the complexity of the problems, much computational effort is needed. In that sense, using 4.0 industry concepts, like artificial intelligence, has been helping companies formulate optimal, or near-optimal, production plans for their process in a feasible time. Since each company has different characteristics and variables, the possibilities to formulate and optimize production planning are diverse. Thus, many case studies can be carried out. Generating a huge range of research opportunities. So, this study is a survey attempting to find some of these gaps through a systemic and bibliometric analysis. To achieve this goal the methodological procedure Knowledge Development Process - Constructivist (ProKnow - C) was used. This method aims to minimize the amount of content out of alignment with the research subject. In the first search, 44,609 articles were found, and after a filtering process that prioritized scientific recognized articles and journals, only 15 articles remained. Finally, common themes among the articles and opportunities for future work were highlighted.
\end{abstract}

Keywords. Artificial intelligence, optimization, production planning

\section{Introduction}

Production Planning is one of the most important strategic decisions that a company can make [1]. It is a fundamental element in cost control at companies. And it determines the quantity and the sequence that products will be produced to accomplish the request in a time horizon [2]. Because of the complexity of this kind of problem, a lot of computational effort is required. In that sense, using 4.0 industry concepts, like artificial intelligence, has been helping companies formulate optimal, or near optimal, production plans for their process in a feasible time [3].

The concept of 4.0 Industry emerged in Germany on 2011. And it became in 2013 an official initiative to revolutionize the German manufacturing system [4]. This concept proposes build a production system super flexible of personalized products and services, with real-time interactions between people, products and the production process [5].

\footnotetext{
${ }^{1}$ Corresponding Author, Email address: ruan@alunos.utfpr.edu.br.
} 
Industry 4.0 can be divided in five main parts: digitalization; production optimization and customization; adaptation and automation; human machine interaction; value-added services and businesses; and automatic data exchange and communication [6].

Since each company has different characteristics and variables, the possibilities to formulate and optimize production planning are diverse. Thus, many case studies can be carried out. Generating a huge range of research opportunities. So, a bibliometric and systemic analysis about Production Planning and Optimization in Industry environment was made seeking to carry out a generalized analysis on the topic and aiming to find common themes among the articles and opportunities for future work.

This article is divided in five sections. In the section 1 is presented the research methodology. In section 2 is presented the process to filter the bibliometric portfolio. In the section 3, the bibliometric review is made. In the section 4, the systemic analysis is presented. Then, in section 5, it contains the conclusion.

\section{Methodological Aspects}

The first thing that researches do to develop a work and build knowledge in some context is a bibliometric review about the subject. Frequently researches have difficulties to find the desired information and lost their time with not essential readings [7]. In that sense, the method ProKnow-C, Knowledge Development Process - Constructivist was used.

The ProKnow-C was developed by the Multicriteria Decision Analysis Laboratory (LabMCDA) of the Federal University of Santa Catarina (UFSC). It is a methodology that pursuit knowledge development structured in four stages. The first stage is the selection of the bibliographic portfolio, the second is the bibliometric analysis of the portfolio, the third is the systemic analysis of the portfolio and the fourth stage is the elaboration of the research opportunities [7].

This method helps to develop the knowledge of the research subject by selecting the most relevant articles. In that sense, is verified the main authors about the theme, the main keywords and the scientific prestige. ProKow-C has been applied in many fields, e.g., public administration and ambient disclosure [7].

\section{Bibliographic portfolio selection}

The first step to start searching articles is defining the search axis. In this work, three axes were defined. The first is Production Planning, the second is Optimization and the third is Manufacturing. The chosen keywords for the first axis were Production Planning and Rolling Horizon; for the second axis were Optimization, Optimal Production and Nesting; and for the third axis were Manufacturing, Supply Chain, Industrial and Metal Industry. To create the search key was necessary to use the Boolean operators "AND" and "OR". So, the search key was ("PRODUCTION PLANNING" OR "ROLLING HORIZON") AND ("OPTIMIZATION" OR "OPTIMAL PRODUCTION" OR "NESTING") AND ("SUPPLY CHAIN" OR "INDUSTRIAL" OR "MANUFACTURING" OR "METAL INDUSTRY").

The next step was to choose the databases to search the articles. In this step, were chosen some of the relevant databases available in the periodical portal of the Coordination of Improvement of Higher Education Personnel (Capes), based on 
correlated areas and the possibility of advanced search. The selected databases were ScienceDirect (Elsevier), Scopus (Elsevier), ProQuest, SAGE Journals, Springer Link, Web of Science and EBSCOhost.

After the selection of the databases, the key search was applied in each database and 44,609 articles were found. In that sense, the use of some filter was necessary to reduce the size of the portfolio. The Figure 1 presents a synthesis of the filtering process.

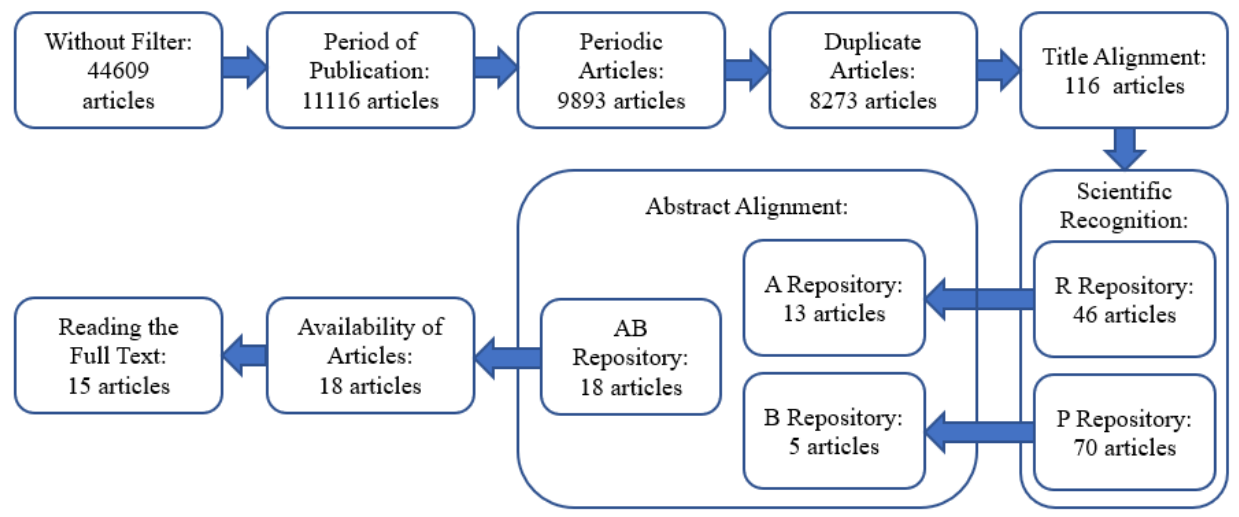

Figure 1. Synthesis of the filtering process.

\subsection{Period of Publication}

Only articles from the last 5 years (2015-2020) were considered, so articles published before 2015 were discarded. In that way, the number of selected articles drop to 11,116 , representing $24.92 \%$ of the initial portfolio. This step aims to choose the most recent articles, avoiding topics that are not relevant at the moment.

\subsection{Periodic Articles}

Only periodic articles were considered. The number of selected articles drop to 9,893 , representing $22.18 \%$ of the initial portfolio.

\subsection{Duplicate Articles}

The portfolio was polluted with repeated articles. These spare articles were deleted, and the portfolio size drops to 8,273 , representing $18.55 \%$ of the initial value.

\subsection{Title Aligment}

In this stage articles that the title did not match with the subject were discarded. Only 116 articles remain in the portfolio representing $0.26 \%$ of the initial portfolio. 


\subsection{Scientific Recognition}

In this stage the portfolio was divided in two groups. The R Repository represents the group of articles that already have proven scientific recognition. And the P Repository represents the articles that do not have relevant scientific recognition. To do this division was necessary collect the number of times that each article was quoted. The articles were ordered from the most quoted to the least quoted. In that way, the most quoted articles that together had $80 \%$ of the total citations were selected to compose the R Repository, totalizing 46 articles. The remaining articles were placed in P Repository, totalizing 70 articles.

\subsection{Abstract Aligment}

At this stage the abstract of all articles from R Repository was read. And the articles that had the abstract aligned with the research subject were placed in the A Repository, totalizing 13 articles. For the P Repository were read the abstracts of the articles published from 2018 onwards or the ones that were written for at least one author belonging to the A Repository. The articles that had their abstracts aligned with the research subject were placed in B Repository, totalizing 5 articles. So was created the AB Repository containing the articles from A Repository and B Repository, totalizing 18 articles and represents $0.04 \%$ of the initial portfolio.

\subsection{Availability of Articles}

All articles from AB Repository had their full text available for access.

\subsection{Reading the full text}

All articles from AB Repository were fully read and 15 articles were selected to compose the bibliographic portfolio of this research, representing $0.03 \%$ of the initial portfolio.

\section{Bibliometric analysis of bibliographic portfolio}

In the bibliometric analysis stage is performed a statistical analysis of the 15 articles belonging to the research portfolio. This step is important because it helps to confirm the scientific relevance of the choosen papers. The first analysis is the journal's relevance. To perform this analysis was compared the number of articles that were published in each article. In that sense, the most relevant journal was Computers and Industrial Engineering, that comprise $20 \%$ of the portfolio. This comparison can be seen in Figure 2. 


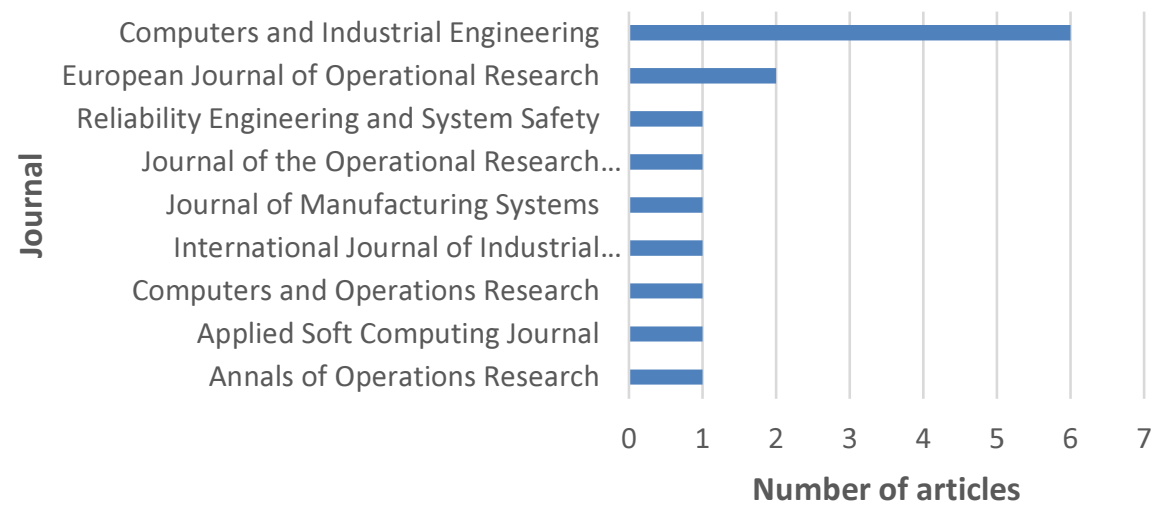

Figure 2. Estimation of journal's relevance.

The Table 1 was developed in order to analyze the scientific recognition of the portfolio. The most quoted article was A possibilistic environment-based particle swarm optimization for aggregate production planning, it was quoted 30 times, representing $11.19 \%$ of the total number of citations. And least quoted article was Aggregate production planning: A literature review and future research directions, that was quoted 6 times, representing $2.24 \%$ of the total number of citations.

Table 1. Number of citations.

\begin{tabular}{lc}
\hline Article & Citations \\
\hline $\begin{array}{l}\text { A possibilistic environment-based particle swarm optimization for aggregate production } \\
\text { planning }\end{array}$ & 30 \\
\hline Production scheduling and nesting in additive manufacturing & 28 \\
\hline $\begin{array}{l}\text { Optimal production planning for assembly systems with uncertain capacities and random } \\
\text { demand }\end{array}$ & 28 \\
\hline $\begin{array}{l}\text { A multi-objective optimization approach for integrated production planning under interval } \\
\text { uncertainties in the steel industry }\end{array}$ & 26 \\
\hline $\begin{array}{l}\text { Optimal production scheduling for hybrid manufacturing-remanufacturing systems with } \\
\text { setups }\end{array}$ & 24 \\
\hline $\begin{array}{l}\text { Mathematical models and a heuristic method for the multiperiod one-dimensional cutting } \\
\text { stock problem }\end{array}$ & 20 \\
\hline $\begin{array}{l}\text { An efficient genetic algorithm with a corner space algorithm for a cutting stock problem in } \\
\text { the TFT-LCD industry }\end{array}$ & 18 \\
\hline $\begin{array}{l}\text { Integrated production planning and scheduling for a mixed batch job-shop based on alternant } \\
\text { iterative genetic algorithm }\end{array}$ & 18 \\
\hline Production planning of new and remanufacturing products in hybrid production systems & 17 \\
\hline $\begin{array}{l}\text { Production planning conflict resolution of complex product system in group manufacturing: } \\
\text { A novel hybrid approach using ant colony optimization and Shapley value }\end{array}$ & 16 \\
\hline $\begin{array}{l}\text { A two-level method of production planning and scheduling for bi-objective reentrant hybrid } \\
\text { flow shops }\end{array}$ & 12 \\
\hline
\end{tabular}




\begin{tabular}{lc}
\hline Article & Citations \\
\hline $\begin{array}{l}\text { Two efficient heuristics to solve the integrated load distribution and production planning } \\
\text { problem }\end{array}$ & 10 \\
\hline $\begin{array}{l}\text { Multi-stage multi-product multi-period production planning with sequence-dependent setups } \\
\text { in closed-loop supply chain }\end{array}$ & 8 \\
\hline $\begin{array}{l}\text { Hybrid simulated annealing and genetic approach for solving a multi-stage production } \\
\text { planning with sequence-dependent setups in a closed-loop supply chain }\end{array}$ & 7 \\
\hline Aggregate production planning: A literature review and future research directions & 6 \\
\hline
\end{tabular}

The 15 articles belonging the portfolio were written by 39 authors. $92.30 \%$ of the authors wrote only one article of the portfolio. Somayeh Torkaman, S.M.T.Fatemi Ghomi and Behrooz Karimi were the only authors that have more than one article written in the portfolio. They have written together 2 articles, representing $12.33 \%$ of the portfolio.

Among the 15 articles of the portfolio, 63 keywords were identified. Only $9.52 \%$ of the keywords were used in more than one article. The most relevant keyword was Production Planning being used 8 times. Followed by Closed-loop supply chain, Flow shop, Genetic algorithm, Reverse logistics and Rolling Horizon being used 2 times each.

In order to analyse the impact factor of the journals the 2018 edition of the Journal Citation Report (JCR) was used. The International Journal of Industrial Engineering Computations was not considered because it does not have a JCR. The journal with the highest JCR was the Applied Soft Computing Journal with impact factor of 4.873. In Figure 3 presents a graphic showing each journal with their respective JCR.

The last analysis is about the year of the publications of the 15 articles of the portfolio. 2015 was the year whit the highest number of publications. Five articles were published in that year, representing $33.33 \%$ of the portfolio. In the Figure 4 is possible to observe the total number of articles of the portfolio published in each year.

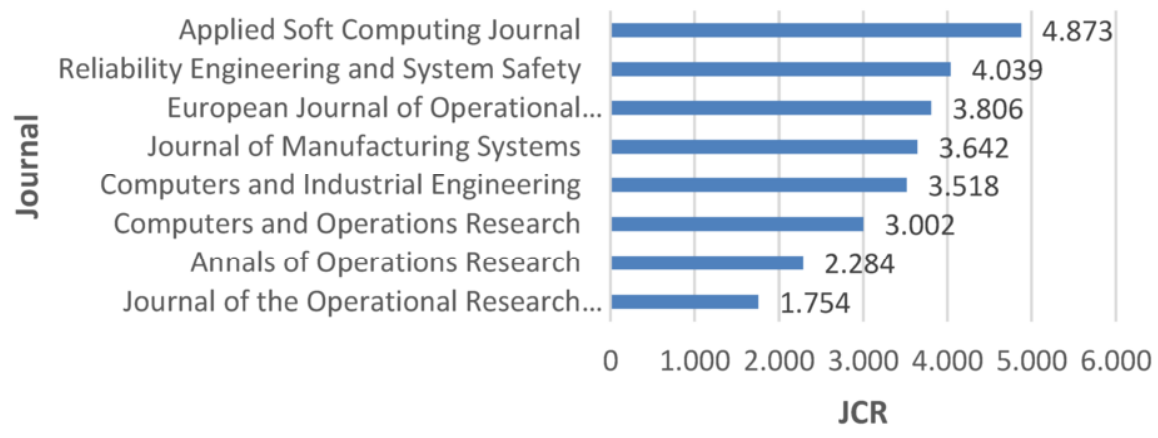

Figure 3. JCR Analysis. 


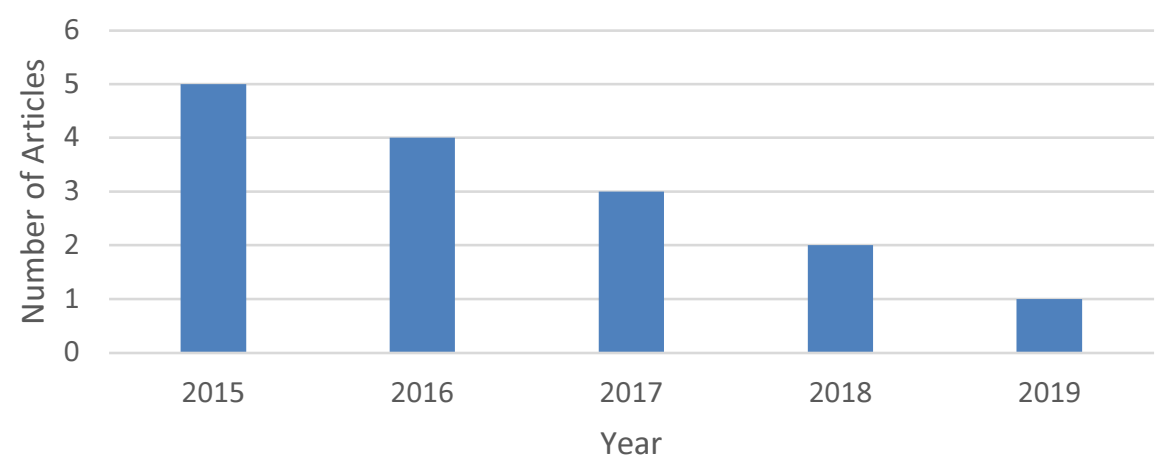

Figure 4. Number of published articles per year.

\section{Systemic analisys and review discussion}

The systemic analysis is important because it seeks to build the knowledge around a broader picture of the research subject. After reading the 15 articles of the portfolio, a content analysis was made. The analysis concerned to find main research problems, the means of solving these problems, trends and future research opportunities.

Production planning problems can be mixed whit many other problems, e.g., nesting in additive manufacture [8], assembly systems with uncertain capacities and random demand [9], complex product systems [3], hybrid flow shops [2], load distribution [10], uncertainties in industry [11], and integrated with scheduling [12]. Those varieties of applications make production planning a subject with many opportunities for future research.

Torkaman, Fatemi Ghomi and Karimi, 2017 [13] e Torkaman, Fatemi Ghomi and Karimi, 2018 [14] try to solve a production planning problem in a closed-loop supply chain. The problem is formulated using mixed integer programming (MIP). In order to solve the model, MIP-based heuristics using rolling horizon were developed. In [13] a simulated annealing algorithm was used to solve the problem. In [14] a hybrid algorithm using simulated annealing algorithm and genetic algorithm was used. For future work is suggested considering the uncertainties related to remanufacturing such as the amount and quality of returned products and reprocessing time, and, solve the problem as a multiobjective problem.

Another problem that has a huge impact in production planning is reverse logistic. Fang, Lai and Huang, 2017 [15] and Polotski, Kenne and Gharbi, 2015 [16] have faced the challenge of coordinate a production system that have new and remanufactured products. These systems are known as hybrid systems. In [16] the focus of research was address the optimal scheduling for hybrid manufacturing-remanufacturing systems with setups. In contrast, in [15] was considered capacity limitation, the durability of the recycled used product, competition between the new and used products, and the maximized total profit. As a future work is proposed incorporating the inventory of the remanufactured product to investigate the impact on the profitability.

Developing a technique which aggregates all the production information is a difficult task. These problem in called Aggregated Production Planning (APP). Chakrabortty et al., 2015 [17] proposed an approach that minimizes the risk to obtain the 
higher total cost and maximizes the possibilities to obtain the lower total cost. To solve the problem in [17] was used particle swarm optimization and genetic algorithm. Cheraghalikhani, Khoshalhan and Mokhtari, 2019 [18] made a review about this subject and for future work was proposed study stochastic and multiple objective models for APP.

According to Poldi and Araujo, 2016 [19] multiperiod cutting stock problem arises in the production planning of many industries. Lu and Huang, 2015 [20] investigated a two-dimensional cutting stock problem in the thin film transistor liquid crystal display industry. Mixed integer programing was used to build the problem. Because of its complexity was necessary use genetic algorithm to find a solution. In [19] was presented a mathematical model to solve a cutting stock problem in which demand occurs along a planning horizon. For future research was proposed to extend the solution to twodimensional cutting stock problems, the inclusion of capacity constraints and integrate lot sizing with cutting stock problem.

Research opportunities were identified through the systemic analysis of the articles. Some of them are shown below:

- Optimize a production planning considering uncertenties on the process and random failures.

- Optimize a production planning considering muti-objectives and using hybrid metaheristcs.

- Optimize a production planning of a cutting stock problem considering a larger range of variables, e.g., transport costs, setup costs and delivery time.

- Optimize a production planning of a hybrid system considering remanufacture products inventory and government regulations.

\section{Conclusion}

Production planning directly affects the efficiency of a company, and because of its complexity, require a lot computational effort. In that sense, 4.0 industry concepts, through artificial intelligence technics, have been helping formulate optimized production plans. A bibliometric and systemic analysis was made seeking to build knowledge about the subject and find research opportunities. The methodology used to conduct this work was ProKnow-C, because it helps to find articles more aligned with the research subject. At the beginning, a lot of articles related with the search key were found. In that sense, the use of some filters was necessary. So, in the end of the bibliographic portfolio selection, only 15 articles were chosen. A bibliometric analysis of the portfolio was made, aiming to discover the scientific relevance of the articles. And finally, a systemic analysis was made to investigate the content of the articles, highlight common themes and find gaps for future work.

\section{Acknowledgement}

The authors wish to thank Fundação de Apoio a Universidade Tecnológica Federal do Paraná for supporting the present research. 


\section{References}

[1] C. Kilger, B. Reuter, and H. Stadtler, "Collaborative planning," in Supply Chain Management and Advanced Planning (Fourth Edition): Concepts, Models, Software, and Case Studies, Springer Berlin Heidelberg, 2008, pp. 263-284.

[2] H. M. Cho and I. J. Jeong, "A two-level method of production planning and scheduling for biobjective reentrant hybrid flow shops," Comput. Ind. Eng., vol. 106, pp. 174-181, 2017.

[3] B. Du and S. Guo, "Production planning conflict resolution of complex product system in group manufacturing: A novel hybrid approach using ant colony optimization and Shapley value," Comput. Ind. Eng., vol. 94, pp. 158-169, 2016.

[4] L. Da Xu, E. L. Xu, and L. Li, "Industry 4.0: State of the art and future trends," Int. J. Prod. Res., vol. 56, no. 8, pp. 2941-2962, 2018.

[5] K. Zhou, T. Liu, and L. Zhou, "Industry 4.0: Towards future industrial opportunities and challenges," in 2015 12th International Conference on Fuzzy Systems and Knowledge Discovery, FSKD 2015, 2015, pp. 2147-2152.

[6] V. Roblek, M. Meško, and A. Krapež, "A Complex View of Industry 4.0," SAGE Open, vol. 6, no. 2, pp. 1-11, 2016.

[7] M. H. F. Afonso, J. V. de Souza, S. R. Ensslin, and L. Ensslin, "Como Construir Conhecimento Sobre O Tema De Pesquisa? Aplicação Do Processo Proknow-C Na Busca De Literatura Sobre Avaliação Do Desenvolvimento Sustentável," Rev. Gestão Soc. e Ambient., vol. 5, no. 2, pp. 47-62, 2012.

[8] A. Chergui, K. Hadj-Hamou, and F. Vignat, "Production scheduling and nesting in additive manufacturing," Comput. Ind. Eng., vol. 126, no. September, pp. 292-301, 2018.

[9] Q. Ji, Y. Wang, and X. Hu, "Optimal production planning for assembly systems with uncertain capacities and random demand," Eur. J. Oper. Res., vol. 253, no. 2, pp. 383-391, 2016.

[10] Y. Gajpal and M. Nourelfath, "Two efficient heuristics to solve the integrated load distribution and production planning problem," Reliab. Eng. Syst. Saf., vol. 144, pp. 204-214, 2015.

[11] J. Lin, M. Liu, J. Hao, and S. Jiang, "A multi-objective optimization approach for integrated production planning under interval uncertainties in the steel industry," Comput. Oper. Res., vol. 72, pp. 189-203, 2016.

[12] H. Sen Yan, X. Q. Wan, and F. L. Xiong, "Integrated production planning and scheduling for a mixed batch job-shop based on alternant iterative genetic algorithm," J. Oper. Res. Soc., vol. 66, no. 8, pp. $1250-1258,2015$.

[13] S. Torkaman, S. M. T. Fatemi Ghomi, and B. Karimi, "Multi-stage multi-product multi-period production planning with sequence-dependent setups in closed-loop supply chain," Comput. Ind. Eng., vol. 113, no. September, pp. 602-613, 2017.

[14] S. Torkaman, S. M. T. Fatemi Ghomi, and B. Karimi, "Hybrid simulated annealing and genetic approach for solving a multi-stage production planning with sequence-dependent setups in a closedloop supply chain," Appl. Soft Comput. J., vol. 71, pp. 1085-1104, Oct. 2018.

[15] C. C. Fang, M. H. Lai, and Y. S. Huang, "Production planning of new and remanufacturing products in hybrid production systems," Comput. Ind. Eng., vol. 108, pp. 88-99, 2017.

[16] V. Polotski, J. P. Kenne, and A. Gharbi, "Optimal production scheduling for hybrid manufacturingremanufacturing systems with setups," J. Manuf. Syst., vol. 37, pp. 703-714, 2015.

[17] R. K. Chakrabortty, M. A. A. Hasin, R. A. Sarker, and D. L. Essam, "A possibilistic environment based particle swarm optimization for aggregate production planning," Comput. Ind. Eng., vol. 88, pp. 366-377, 2015.

[18] A. Cheraghalikhani, F. Khoshalhan, and H. Mokhtari, "Aggregate production planning: A literature review and future research directions," International Journal of Industrial Engineering Computations, vol. 10, no. 2. Growing Science, pp. 309-330, 01-Apr-2019.

[19] K. C. Poldi and S. A. de Araujo, "Mathematical models and a heuristic method for the multiperiod one-dimensional cutting stock problem," Ann. Oper. Res., vol. 238, no. 1-2, pp. 497-520, 2016.

[20] H. C. Lu and Y. H. Huang, An efficient genetic algorithm with a corner space algorithm for a cutting stock problem in the TFT-LCD industry, Eur. J. Oper. Res., vol. 246, no. 1, pp. 51-65, 2015. 